\title{
Testing of a New Collagenase Blend for Pancreatic Islet Isolation Produced by Clostridium histolyticum
}

\author{
Zuzana Berková ${ }^{1}$, František Saudek ${ }^{1,2}$, Ivan Leontovyč ${ }^{1}$, Martin Benešík ${ }^{3}$, Dana Štveráková ${ }^{3}$ \\ ${ }^{1}$ Laboratory of Pancreatic Islets, Institute for Clinical and Experimental Medicine, Prague, Czech Republic \\ ${ }^{2}$ Department of Diabetes, Institute for Clinical and Experimental Medicine, Prague, Czech Republic \\ ${ }^{3}$ MB Pharma Ltd., Prague, Czech Republic \\ Email: zube@ikem.cz
}

How to cite this paper: Berková, Z., Saudek, F., Leontovyč, I., Benešík, M. and Štveráková, D. (2018) Testing of a New Collagenase Blend for Pancreatic Islet Isolation Produced by Clostridium histolyticum. Advances in Bioscience and Biotechnology, 9, 26-35.

https://doi.org/10.4236/abb.2018.91003

Received: December 15, 2017

Accepted: January 26, 2018

Published: January 29, 2018

Copyright $(9) 2018$ by authors and Scientific Research Publishing Inc. This work is licensed under the Creative Commons Attribution International License (CC BY 4.0).

http://creativecommons.org/licenses/by/4.0/

\begin{abstract}
Clostridium histolyticum is used for production of several proteolytic enzymes such as elastase, neutral proteases, clostripain and in particular collagenase. Besides industrial applications, collagenase has been indispensable for medical purposes including isolation of pancreatic islets for diabetes treatment. The aim of this study was to optimize the method for production and partial purification of a new collagenase blend and to test its suitability for successful pancreatic islets isolation in a rat model. Bacterial strain of C. histolyticum was sequenced for presence of the collagenase genes. Different fermentation conditions were tested and the process of collagenase extraction was modified and optimized. Samples of collagenases were taken for western blot detection, activity assessment, and ability for dissociation of pancreatic tissue. Findings indicate that concentrated trypton growth medium with pepton was the most suitable for Clostridium growth and collagenase production. Whole genome sequencing revealed two genes for collagenase and also gene for clostripain. Western blot specific detection helped to select useful production modifications. Following these modifications was also improved the yield, morphology and in vitro function of intact pancreatic islets which were finally comparable or better than those achieved using standard blends of collagenase. The results support the use of the new collagenase blend for islet isolation giving thus the opportunity to choose an alternative product. Our next steps would lead to further enzyme purification through scaling up of the production method for a wider use.
\end{abstract}

\section{Keywords}

Clostridium histolyticum, Fermentation, Collagenase, Pancreatic Islets, Islet Isolation 


\section{Introduction}

Enzymes in general are of fundamental importance in food, cosmetic and pharmaceutical industry due to their activity and wide substrate specificity. Collagenases have the ability to break down the peptide bonds in collagen, which is present in all animal tissues and consists of three polypeptide chains wound in a triple helical structure. Microbial collagenases split each polypeptide chain of collagen at multiple sites [1] and are able to hydrolyze both water-insoluble native and water-soluble denaturated collagen [2]. The research in the last decades has been focused on collagenase characterization and isolation from different tissues of variety of animals as well as from diverse species of microorganisms.

One of the most important and studied producers of collagenase is Clostridium [1] [2] [3]. Clostridium histolyticum is an anaerobic, pathogenic, gram-positive peritrichal bacterium. Straight sticks of bacteria $((0.5-0.9) \times(1.3-9.2) \mu \mathrm{m})$ are forming couples or short strings. Variety of proteolytic enzymes as collagenases, elastase, clostripain and neutral proteases are produced by Clostridium. Collagenases, a zinc-dependent metalloproteases, are divided into the two classes: Class I, encoded by gene ColG, and class II, encoded by gene ColH. Molecular weight of different collagenase isoforms ranged from 68 to $130 \mathrm{kDa}$. In this study was used Clostridium histolyticum MB 204 (owner MB Pharma Ltd., Prague, Czech Republic), a bacterial strain selected by long-term passaging of different bacterial strains during adaptive laboratory evolution (DSM 627, DSM 1126 and DSM 2158 obtained from German microorganism collection).

Currently, the collagenase digestion method is the only way for successful pancreatic islets isolation from the surrounding acinar tissue for experimental as well as clinical purposes [4]. The enzyme is injected into the pancreatic duct of the exocrine system with the aim to selectively dissociate the pancreatic tissue and obtain intact pancreatic islets which constitute only $1 \%$ of the whole pancreas. Collagen is distributed within the pancreatic parenchyma and represents a major part of connective tissue fibers in capsule surrounding pancreatic islets; therefore collagenase is highly essential for islet release from pancreatic tissue. Important parameters for successful isolation are specific collagenolytic activity, possible presence of other proteolytic enzymes, absence of ballast or toxic substances, and of course the isolation costs.

Successful pancreatic islets isolation depends on many important factors [5] including digestion phase with the use of collagenase. While for clinical islet isolation only few more or less approved collagenase products have been accepted, for experimental purposes it is possible to use less purified and less expensive blends for achieving satisfactory results. At the present time, the batch to batch variability of commonly used crude collagenases for pancreatic islet isolations is caused by irregular concentrations of several proteases (collagenases, clostripain and neutral proteases). Assays for collagenase activity cannot accurately reflect the digestion effectiveness in vivo and for each new batch it is necessary to optimize the digestion phase in terms of concentration and duration. As the isolation outcome strongly depends on the enzyme efficacy, constant composition 
and declared activity of the enzymatic product is desirable. The purpose of this study was to test the new blend of collagenase developed by MB Pharma and to contribute by feed-back information to improvement of the production technology.

\section{Materials and Methods}

\subsection{Clostridium histolyticum and Collagenase Preparation}

Clostridium histolyticum MB 204 was retained deep-frozen at $-80^{\circ} \mathrm{C}$ or as lyofilizate at $4^{\circ} \mathrm{C}$. After thawing, bacterial strain was cultured in trypton growth medium: Trypton $60 \mathrm{~g} / \mathrm{l}$, pepton $1.5 \mathrm{~g} / \mathrm{l}$, glucose $1.25 \mathrm{~g} / \mathrm{l}, \mathrm{Na}_{2} \mathrm{HPO}_{4} 3.4 \mathrm{~g} / \mathrm{l}$, collagen $50 \mathrm{~g} / \mathrm{l}$ with vitamin $\mathrm{K} 0.01 \%$ and $\mathrm{L}$-cystein $0.53 \mathrm{~g} / \mathrm{l}(\mathrm{pH} 8.4)$ for 24 hours at $37^{\circ} \mathrm{C} \pm$ $1^{\circ} \mathrm{C}$ in anaerobic conditions. After that Clostridium was cultured in fermentor at the same conditions and pH $7.8 \pm 0.5$ till the bacterial growth was visible. Proteins in medium with bacteria were precipitated by $70 \%$ ammonium sulfate for 4 7 days at $4^{\circ} \mathrm{C}$ and $\mathrm{pH} 6.8$ - 7.6. Supernatant was removed and the sediment with the bacteria and their metabolites including collagenase was dialyzing in $0.5 \mathrm{mM}$ Tris- $\mathrm{HCl}$ buffer ( $\mathrm{pH} 9.5$ ) for 24 hours and in $0.5 \mathrm{mM}$ Tris- $\mathrm{HCl}$ buffer ( $\mathrm{pH} 7.5$ ) for additional 48 hours. Dialysis product was centrifugated at $3500 \times \mathrm{g}$ for 45 minutes and supernatant was filtered through $0.45 \mu \mathrm{m}$ filter for removing bacterial cell debris. Ultrafiltration was performed mostly on $30 \mathrm{kDa}$ Pellicon XL cassettes (Merck Millipore, Germany) or in combination with $300 \mathrm{kDa}, 50 \mathrm{kDa}$ or $10 \mathrm{kDa}$ cassettes to remove ballast proteins and to concentrate and reduce the volume of lyzate. After final filtration through $0.45 \mu \mathrm{m}$ filter the product was lyophilized and ready for use.

\subsection{Bacterial Genome Sequencing}

The bacterial genome of $C$. histolyticum strains were sequenced using the Nextera XT DNA Sample Preparation kit and MiSeq Reagent Kit v3 in the MiSEQ system (Illumina, USA). Obtained reads were assembled into contigs by de novo assembler in CLC. Rast were used for automatic annotation of contigs.

\subsection{Assessment of Collagenase Activity}

Collagenase activity was determined using spectroscopic method that measures collagenase cleavage of synthetic substrate Pz-PLGPR

(p-phenylazobenzyloxycarbonyl-L-prolyl-L-leucyl-glycyl-L-prolyl-D-arginine) [6]. The assay was performed in $100 \mathrm{mM}$ Tris buffer ( $\mathrm{pH}$ 7.1). After 15 minutes of enzymatic reaction, yellow tripeptide fragment of $\mathrm{Pz}$ substrate was extracted into the ethyl acetate and absorbance was measured at $320 \mathrm{~nm}$. Collagenase activity was defined as amount of degraded substrate micromoles by one gram of enzyme in one minute at $25^{\circ} \mathrm{C}$ and expressed as PZS/g.

\subsection{Western Blot}

Western blot analysis [7] was performed on samples of lyophilized collagenase 
dissolved in Hank's balanced salt solution (HBSS) (Sigma-Aldrich, USA) in concentration range 68 - $1360 \mu \mathrm{g}$ of total protein per well. Protein concentration was measured by BCA Protein Assay Kit (Thermo Fisher Scientific, USA). Samples were mixed with $4 \times$ Laemmli loading buffer containing $8 \%$ SDS, $40 \%$ glycerol, $0.02 \%$ bromophenol blue, $250 \mathrm{mM}$ Tris, and 20\% 2-mercaptoethanol (all from Sigma-Aldrich), $\mathrm{pH} 6.8$, heated at $95^{\circ} \mathrm{C}$ for $3 \mathrm{~min}$, and run on a $10 \%$ polyacrylamide gel and transferred to PVDF membranes (Merck) using a Pierce G2 electroblotter (Thermo Fisher Scientific). The membranes were blocked with 3\% BSA (Sigma-Aldrich).

Primary antibody rabbit anti-collagenase (Abcam, UK) for detecting collagenase (1:1000 dilution) and secondary antibody goat anti-rabbit IgG-HRP (Merck Millipore) (1:10,000 dilution) were used. Chemiluminescent Super Signal West Dura Extended Duration Substrate (Thermo Fisher Scientific) was used for detection. The signals were acquired using a G:BOX Chemi XR5 (Syngene, UK).

\subsection{Pancreatic Islet Isolation and Quality Testing}

All experimental protocols were approved by Experimental Animals Welfare Committee of the Institute for Clinical and Experimental Medicine and the Ministry of Health of the Czech Republic in accordance with the European Communities Council Directive 86/609/EEC.

Wistar rats were used as pancreatic islets donors. All surgical procedures were performed in a general anesthesia by intramuscular application of Dexmedetomidine $0.25-0.5 \mathrm{mg} / \mathrm{kg}$ and Ketamine $50 \mathrm{mg} / \mathrm{kg}$ b.w. The pancreas was perfused with $15 \mathrm{ml}$ of collagenase solution: Collagenase (Sigma-Aldrich) or novel collagenases (MB pharma, Czech Republic) and digestion was carried out at $37^{\circ} \mathrm{C}$. Pancreatic islets were separated from exocrine tissue by centrifugation in a discontinuous Ficoll gradient. Isolated islets were then cultured in CMRL-1066 medium (PAN-Biotech GmbH, Germany) supplemented with 10\% FBS, 5\% HEPES, $1 \%$ Glutamax and $1 \%$ penicilin-streptomycin solution (all reagents from Sigma-Aldrich), in a humidified incubator at $37^{\circ} \mathrm{C}$ and a $5 \% \mathrm{CO}_{2}$ atmosphere.

The quality of isolated islets was assessed by differential staining of live/dead cells and by glucose stimulated insulin secretion, as previously described [8]. Briefly, islet vitality was evaluated after staining with propidium iodide (dead red cells) and acridine orange (live green cells). The in vitro function of the isolated islets was measured as insulin secretion in Krebs's solution with low glucose (3 $\mathrm{mmol} / \mathrm{l})$, high glucose $(22 \mathrm{mmol} / \mathrm{l})$, and then low glucose again. At the end of each incubation period, an aliquot of medium was collected for insulin radioimmunoassay using ${ }^{125}$ I RIA Kit (ICN Pharmaceuticals, USA). Results were expressed as stimulation indices.

\subsection{Statistical Analyses}

Results are expressed as mean \pm SD. Lilliefors test for normality was performed to test a normal distribution of our data. Based on normality the Mann-Whitney 
$U$ test was used. A P value $<0.05$ was considered as statistically significant.

\section{Results}

Although PCR confirmed the presence of collagenase gene, whole genome sequencing could better characterize Clostridium histolyticum strains. Sequencing results of C. histolyticum MB 204 revealed two genes for collagenase: ColG encoding collagenase class I (C1) with molecular weight $126.2 \mathrm{kDa}$ and ColH encoding collagenase class II (C2) with molecular weight $116.3 \mathrm{kDa}$ and gene for clostripain with molecular weight $43.4 \mathrm{kDa}$. Genome sequencing of two other bacterial strains was done as well. C. histolyticum MB 201 similar to strain DSM 1126 had one copy of ColG and two copies of ColH genes while on the contrary C. histolyticum MB 202 similar to strain DSM 627 had two copies of gene ColG and one copy of ColH. Based on the results of collagenase activity the strain MB 204 was chosen for this experimental study.

To optimize fermentation and to enhance collagenase production, different growth media were tested: Trypton medium with beef extract, brain heart infusion (BHI), pepton or concentrated trypton medium. The best conditions for bacterial growth and also the highest collagenase production was achieved by concentrated trypton medium with pepton as it was evaluated by collagenase activity assessment (see Table 1).

To eliminate the loss of collagenase during fermentation, bacteria optical density was measured along with collagenase activity. Loss of enzyme occurred during the stationary phase of bacterial growth; therefore shorter fermentation and fresh medium addition were tested. We found out that optimal bacteria fermentation should take approximately 28 - 30 hours, while longer fermentation require fresh growth medium addition to improve culture condition and enhance or maintain collagenase production by bacteria. Supply of concentrated media during fermentation increased collagenase activity from 210 - $350 \mathrm{PZS} / \mathrm{g}$ to 780 PZS/g.

During the process of collagenase extraction, samples were taken and collagenase activity was tested to reveal critical points of the purification method. We found out that after ammonium sulfate precipitation considerable amount of collagenase remained in supernatant. Skipping this step had fatal consequences, a significant decrease in collagenase activity ranged from 54 to $80 \mathrm{PZS} / \mathrm{g}$. Conversely, as the most effective was centrifugation to discard bacteria before precipitation with collagenase activity enhancement to $702 \mathrm{PZS} / \mathrm{g}$.

Table 1. Assessment of collagenase activity in different growth media.

\begin{tabular}{cc}
\hline Growth Medium & Collagenase Activity (PZS/g) \\
\hline Trypton growth medium with beef extract & 30 \\
Trypton growth medium with BHI & 214 \\
Trypton growth medium with pepton & 323 \\
Concentrated trypton growth medium with pepton & 1027
\end{tabular}


The obtained results also revealed that dialysis time can significantly influence the final collagenase activity. We found out that optimal dialysis time was 80 - 90 minutes, shortened dialysis time resulted in decreased collagenase activity and similarly also increased dialysis time considerably reduced collagenase activity.

Ultrafiltration was used to remove ballast proteins and $50 \mathrm{kDa}, 30 \mathrm{kDa}$ and 10 $\mathrm{kDa}$ cassettes alone or in combination with $300 \mathrm{kDa}$ cassette were tested. However the results showed big diversity in collagenase activity in dependence on the cut off cassettes, optimal was combination of $300 \mathrm{kDa}$ with $30 \mathrm{kDa}$ cassette.

Although collagenase activity was measured in all tested batches, detection of correct molecular weight $(126 \mathrm{kDa})$ was performed as well. Samples were analyzed by western blotting to determine the intact collagenase or potential fragmentation (see Figure 1). Our results revealed samples of collagenases with no intact whole enzyme and simultaneously with no degradation fragments (Figure $1(\mathrm{a}))$. Moreover, samples with no collagenase but only fragmentation of the enzyme (Figure 1(b)) as well as samples with intact enzyme and no fragments (Figure 1(c)) were detected. Finally, one batch (Figure 1(d)) contained band corresponding to the size of the intact collagenase together with specific fragments of approximately $50 \mathrm{kDa}$.

The suitability of novel collagenases for pancreatic islet isolation was evaluated as digestion time and islet yield, two the most important steps of the isolation process. The results were divided into 3 groups according the isolation outcome: Group 1: Batches unsuitable for islet isolations; Group 2: Batches with longer digestion time and smaller islet yield and Group 3: Batches with similar digestion time but higher islet yield in comparison to standard collagenase (see Table 2). Significant differences of digestion time were seen in Group 1 and in Group $2(P<0.001)$. In both mentioned groups there was lower number of

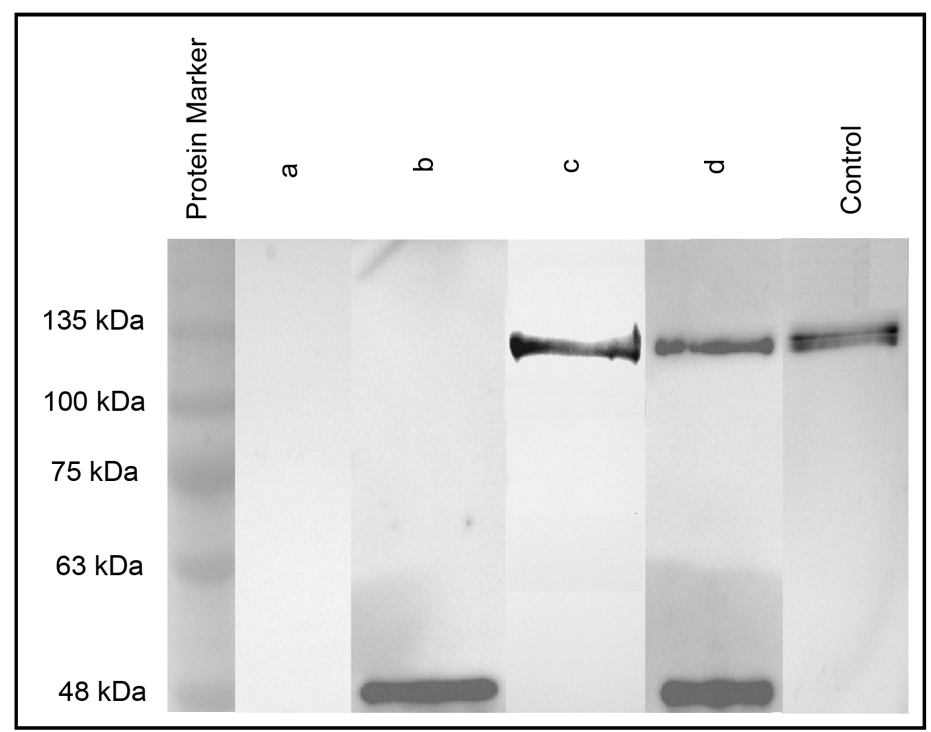

Figure 1. Representative western blot. (a) No intact collagenase and no fragments; (b) Degradation fragments of collagenase; (c) Intact collagenase; (d) Intact collagenase with specific fragments. 
isolated islets in comparison to standard collagenase, nevertheless significant difference was observed only in Group $1(P<0.01)$.

In vitro analysis of the islet quality in Group 1 was not performed due to small number of isolated islets or none. Vitality of the isolated islets in Group 2 and 3 was comparable in majority of measurements (see Table 3). Significant difference between novel and standard collagenase was found only in Group 2 after 24 hours of cultivation $(P<0.01)$. Furthermore, analyses of the glucose stimulated insulin secretion assessed as stimulation index (see Table 4 ) revealed significant difference only in Group $2(P<0.01)$.

Table 2. Comparison of the selected characteristics of the islet isolations.

\begin{tabular}{ccc}
\hline Collagenase Batches & Digestion Time $(\mathrm{min})$ & Islet Yield \\
\hline Group 1 & $47.5 \pm 10.1^{* * *}$ & $113.9 \pm 247.1^{* *}$ \\
Control & $17.0 \pm 2.5$ & $873.8 \pm 217.2$ \\
\hline Group 2 & $21.5 \pm 2.9^{* * *}$ & $657.1 \pm 258.1$ \\
Control & $15.8 \pm 2.8$ & $835.5 \pm 165.1$ \\
\hline Group 3 & $16.3 \pm 2.4$ & $1147.2 \pm 231.1$ \\
Control & $16.3 \pm 2.8$ & $905.0 \pm 257.9$ \\
\hline
\end{tabular}

${ }^{\star *}$ Denotes $P<0.01 .{ }^{* * *}$ Denotes $P<0.001$.

Table 3. Pancreatic islet vitality assessed by differential staining of live/dead cells.

\begin{tabular}{cccc}
\hline $\begin{array}{c}\text { Collagenase } \\
\text { Batches }\end{array}$ & Vitality after Isolation & $\begin{array}{c}\text { Vitality after 24 Hours } \\
\text { Cultivation }\end{array}$ & $\begin{array}{c}\text { Vitality after 7 Days } \\
\text { Cultivation }\end{array}$ \\
\hline Group 1 & N/A & N/A & N/A \\
Control & $91.4 \pm 2.9$ & $86.7 \pm 2.6^{* *}$ & $93.8 \pm 3.0$ \\
Group 2 & $92.5 \pm 1.9$ & $91.3 \pm 1.7$ & $93.7 \pm 1.9$ \\
Control & $92.5 \pm 2.1$ & $92.7 \pm 2.4$ & $92.8 \pm 2.7$ \\
Group 3 & $93.8 \pm 2.9$ & $91.9 \pm 1.6$ & $93.6 \pm 2.6$ \\
Control & & & \\
\hline
\end{tabular}

${ }^{*}$ Denotes $P<0.01 . \mathrm{N} / \mathrm{A}=$ not available.

Table 4. Glucose stimulated insulin secretion assessed as stimulation index.

\begin{tabular}{cc}
\hline Collagenase Batches & Stimulation Index \\
\hline Group 1 & N/A \\
Control & $5.3 \pm 2.5^{\star}$ \\
\hline Group 2 & $8.9 \pm 5.1$ \\
Control & $8.1 \pm 3.4$ \\
\hline Group 3 & $10.3 \pm 4.1$ \\
\hline Control & \\
\hline
\end{tabular}

${ }^{\star}$ Denotes $P<0.05 . \mathrm{N} / \mathrm{A}=$ not available. 


\section{Discussion}

In this study we systematically studied the activity of a new collagenase product which was being developed by MB Pharma (Prague, Czech Republic). Sequencing of bacterial genomes revealed collagenase genes duplicity in two strains ( $\mathrm{MB}$ 201 and MB 202), while in the strain MB 204 deletion of one copy of collagenase gene was confirmed. For production, the strain with only a single collagenase gene set was selected because of its high collagenase production rate, probably due to a stronger promoter activity. Collagenase from the selected strain was used for pancreatic islet isolation and the parallel results were used as a feed-back for modification of the culture and purification method in order to achieve stable results in terms of the islet isolation outcome. The final product now can be recommended for islet isolation in a rat model.

Pancreatic tissue dissociation by bacterial collagenases still remains the most important step in islet isolations. Effectiveness of collagenase to degrade extracellular matrix (ECM) proteins is crucial for the release of pancreatic islets from surrounding tissue. Crude collagenases commonly used for experimental islet isolations contain both collagenase isoforms in different rate together with other proteases. Clostridium collagenases $\mathrm{C} 1$ and $\mathrm{C} 2$ hydrolyze collagen chains sequentially from the ends into mixture of small peptides [9]. It was reported that C2 was more efficient in collagen degradation [10] whereas C1 played only supporting role in islet isolations [11]. Study by Brandhorst et al. [12] showed that neither $\mathrm{C} 1$ nor $\mathrm{C} 2$ alone were able to dissociate pancreatic tissue. Rapid and complete loss of peri-islet ECM depends on both collagenase isoform and is best achieved with assistance of other proteolytic enzymes [10] [12] [13]. This conclusion was also confirmed in our study, where the best results were achieved with a batch from Group 3 containing intact and fragmented collagenase in combination with neutral protease (NP) and clostripain. Previously published studies [11] [13] showed that NP and clostripain can compensate reduced C1 activity; however the results of our study revealed successful islet isolations with batches without the presence of collagenase. Potentially deteriorate influence of NP on islet viability was not fully confirmed in our study except decreased vitality and lover glucose stimulated insulin secretion 24 hours after isolation in Group 2 but not in Group 3. Specific detection of collagenase using western blot revealed fragmented collagenase mostly in Group 2 and surprisingly intact collagenase in Group 1. This discrepancy could be explained by collagenase precipitation, however intact collagenase was detected on SDS page and western blot, collagenase was inactive as it was confirmed by very low collagenase activity and inability to isolate pancreatic islet.

At the present time, there are many different assays for measuring collagenase activity. Hydrolysis of Pz-peptides belongs to one of the broadly used and sensitive methods. Disadvantage of this method is poor measurement of C1 collagenase and that cannot discriminate between intact and degraded collagenase. This method reflects only the function of catalytic domain; therefore measured colla- 
genase activity in vitro cannot exactly predict the activity in vivo and isolation outcome as well. Collagenase activity was detected also in batches without collagenase, probably due to capability to hydrolyze synthetic substrate by other proteases.

In this study we found out that the loss of enzyme occurred in few critical points of the process of Clostridium fermentation and collagenase purification. These points were solved by specific modifications during the fermentation and purification processes. However, we are aware that for possible use in human islet isolation, higher grade of collagenase purification and efficacy confirmation will be needed. Our experimental work thus represents a prerequisite for scaling up of the collagenase production and for development of further steps in purification and standardization.

\section{Acknowledgements}

This study was supported by MH CZ - DRO ("Institute for Clinical and Experimental Medicine-IKEM, IN 00023001”), by grant no. TA04010038 from Technology Agency of the Czech Republic and by grant no. FV20139 from Ministry of Industry and Trade.

\section{References}

[1] MacLennan, J.D., Mandl, I. and Howes, E.L. (1953) Bacterial Digestion of Collagen. Journal of Clinical Investigation, 32, 1317-1322. https://doi.org/10.1172/JCI102860

[2] Mookhtiar, K.A. and Van Wart, H.E. (1992) Clostridium histolyticum Collagenases: A New Look at Some Old Enzymes. Matrix Supplement, 1, 116-126.

[3] Bond, M.D. and Van Wart, H.E. (1984) Characterization of the Individual Collagenases from Clostridium histolyticum. Biochemistry, 23, 3085-3091. https://doi.org/10.1021/bi00308a036

[4] Ricordi, C., Lacy, P.E., Finke, E.H., Olack, B.J. and Scharp, D.W. (1988) Automated Method for Isolation of Human Pancreatic Islets. Diabetes, 37, 413-420. https://doi.org/10.2337/diab.37.4.413

[5] Berkova, Z., Saudek, F., Girman, P., Zacharovova, K., Kriz, J., Fabryova, E., Leontovyc, I., Koblas, T., Kosinova, L., Neskudla, T., Vavrova, E., Habart, D., Loukotova, S., Zahradnicka, M., Lipar, K., Voska, L. and Skibova, J. (2016) Combining Donor Characteristics with Immunohistological Data Improves the Prediction of Islet Isolation Success. Journal of Diabetes Research, 7, Article ID: 4214328. https://doi.org/10.1155/2016/4214328

[6] Wünsch, E. and Heinrich, H.G. (1963) Zur Quantitativen Bestimmung der Kollagenase. Hoppe-Seylers Zeitschrift für Physiologische Chemie, 333, 149-151. https://doi.org/10.1515/bchm2.1963.333.1.149

[7] Leontovyc, I., Habart, D., Loukotova, S., Kosinova, L., Kriz, J., Saudek, F. and Koblas, T. (2017) Synthetic mRNA Is a More Reliable Tool for the Delivery of DNA-Targeting Proteins into the Cell Nucleus than Fusion with a Protein Transduction Domain. PLoS ONE, 12, e0182497. https://doi.org/10.1371/journal.pone.0182497

[8] Zacharovova, K., Berkova, Z., Spacek, T., Kriz, J., Dovolilova, E., Girman, P., Koblas, T., Jezek, P. and Saudek, F. (2005) In Vitro Assessment of Pancreatic Islet Vitality by Oxymetry. Transplantation Proceedings, 37, 3454-3456. 
https://doi.org/10.1016/j.transproceed.2005.09.053

[9] French, M.F., Mookhtiar, K.A. and Van Wart, H.E. (1987) Limited Proteolysis of Type I Collagen at Hyperreactive Sites by Class I and II Clostridium histolyticum Collagenases: Complementary Digestion Patterns. Biochemistry, 26, 681-687. https://doi.org/10.1021/bi00377a004

[10] Vos-Scheperkeuter, G.H., van Suylichem, P.T., Vonk, M.W., Wolters, G.H. and van Schilfgaarde, R. (1997) Histochemical Analysis of the Role of Class I and Class II Clostridium histolyticum Collagenase in the Degradation of Rat Pancreatic Extracellular Matrix for Islet Isolation. Cell Transplantation, 6, 403-412. https://doi.org/10.1177/096368979700600407

[11] Fujio, A., Murayama, K., Yamagata, Y., Watanabe, K., Imura, T., Inagaki, A., Ohbayashi, N., Shima, H., Sekiguchi, S., Fujimori, K., Igarashi, K., Ohuchi, N., Satomi, S. and Goto, M. (2013) Collagenase H Is Crucial for Isolation of Rat Pancreatic Islets. Cell Transplantation, 23, 1187-1198. https://doi.org/10.3727/096368913X668654

[12] Brandhorst, H., Raemsch-Guenther, N., Raemsch, C., Friedrich, O., Huettler, S., Kurfuerst, M., Korsgren, O. and Brandhorst, D. (2008) The Ratio Between Collagenase Class I and Class II Influences the Efficient Islet Release from the Rat Pancreas. Transplantation, 85, 456-461.

[13] Brandhorst, H., Kurfürst, M., Johnson, P.R., Korsgren, O. and Brandhorst, D. (2015) Comparison of Neutral Proteases and Collagenase Class I as Essential Enzymes for Human Islet Isolation. Transplantation Direct, 2, e47. https://doi.org/10.1097/TXD.0000000000000552 